\title{
Clinical and histopathological study of a rare sinonasal glomangiopericytoma: a case report
}

Taha M. Abdelaal

Department of Otorhinolaryngology, Benha University, Benha, Egypt

Correspondence to Taha M. Abdelaal, MD, Department of Otorhinolaryngology, Benha University, Atreeb, Mohamed Al Gazar Street, Dr. Mohamed El Sayed Building Opposite to Anas Bin Malik Shool, Benha, 13511, Egypt. Mob: 00201114015115;

e-mail: tahaabdelaal2020@gmail.com

Received 11 June 2018

Accepted 28 June 2018

The Egyptian Journal of Otolaryngology 2018, 34:345-350

\begin{abstract}
A 42 year old female patient visited our clinic with reports of a 5 month history of progressive nasal obstruction, associated later with decreased smell sensitivity and left ear block. Routine rhinoscopic and endoscopic examinations revealed a greyish polypoid mass of the left nasal cavity. CT showed a hypervascular mass lesion obliterating the left nasal cavity which was compressing the medial wall of the ipsilateral maxillary sinus. MRI confirmed CT findings of a hypervascular lesion, with MRA identifying the left internal maxillary artery branch as the mainfeeding vessel. Endoscopic surgical excision was performed, with preoperative embolization done prior to excision, to reduce intra-operative blood loss and facilitate complete excision. Histopathology confirmed sinsonasal glomangipericytoma. The patient did not present with any of the known predisposing risk factors and the etiology of the tumor remains unknown. Although it is thought that the incidence of recurrence is low following complete excision, the reported recurrence of $9.5 \%$ to $50 \%$ necessitates life long follow up.
\end{abstract}

\section{Keywords:}

endoscopic, glomangiopericytoma, histopathology

Egypt J Otolaryngol 34:345-350

(C) 2018 The Egyptian Journal of Otolaryngology

1012-5574

\section{Introduction}

Glomangiopericytoma was initially diagnosed by Stout and Murray. They defined it as hemangiopericytoma. In 1976 it was described by Compagno as 'hemangiopericytoma like' due to the low incidence of metastasis and mortality [1]. Recently in 2005 the WHO classified it as a unique glomagiopericytoma due to its close similarity to glomus tumor [2].

Glomagiopericytoma is considered to have borderline low malignant potential. It originates from a perivascular modified glomus-like myoid cell (pericytes) of the sinonasal tract [3]. It accounts for less than $0.5 \%$ of the sinonasal neoplasm [4,5]. Malignant glomangiopericytoma, though uncommon, will appear larger in size with bone invasion and shows profound nuclear pleomorphism with increased mitotic activity and necrosis on histological examination [6].

\section{Case report}

A 42-year-old female patient visited our ENT department reporting progressive left-sided nasal obstruction (partial to complete) for 5 months. During the latter 2 months, she noticed decreased smell perception as well as left ear pressure and block initially was mild and gradually increasing in intensity. No history of epistaxis was reported.

Routine rhinoscopic and endoscopic examination revealed a left-sided grayish pink polypoid mass occupying the left nasal cavity medial and posterior to the face of the middle turbinate totally occluding the posterior nasal cavity and olfactory area (Fig. 1). Right endoscopic examination of the nose showed that the mass was extending and filling the nasopharynx even bulging into the right posterior choana (Fig. 2).

Otoscopic examination of the left ear revealed a retracted tympanic membrane with decreased mobility on pneumatic otoscopy. Rinne test was negative on the left ear and Weber test was shifted to the left ear. There were no palpable lymph nodes on neck examination.

Computed tomography with and without contrast was done. It showed well-defined, expansile, hypervascular mass lesion originating from and obliterating the left nasal cavity measuring about $5.5 \times 4 \times 2.5 \mathrm{~cm}$, extending posteriorly and superiorly to obliterate the left sphenoethmoidal recess and the nasopharynx, predominantly on the left side. The mass lesion was compressing and remodeling the medial wall of the left maxillary sinus. Secondary obstructive changes were seen in all paranasal sinuses on the affected side. Part of the mass was extending superiorly into the left posterior ethmoidal and sphenoid sinuses (Figs 3 and 4).

This is an open access journal, and articles are distributed under the terms of the Creative Commons Attribution-NonCommercial-ShareAlike 4.0 License, which allows others to remix, tweak, and build upon the work non-commercially, as long as appropriate credit is given and the new creations are licensed under the identical terms. 
Figure 1

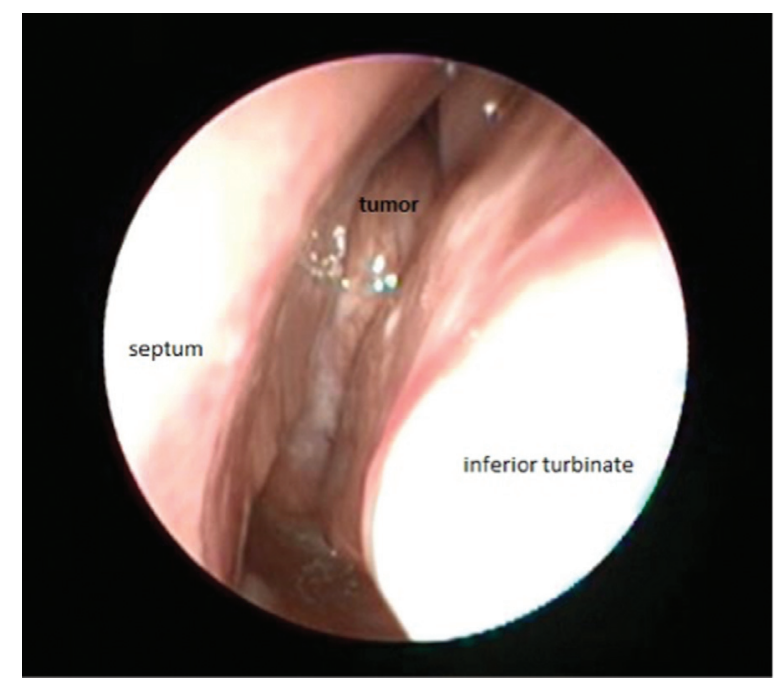

The tumor completely occludes the posterior nasal cavity.

\section{Figure 3}

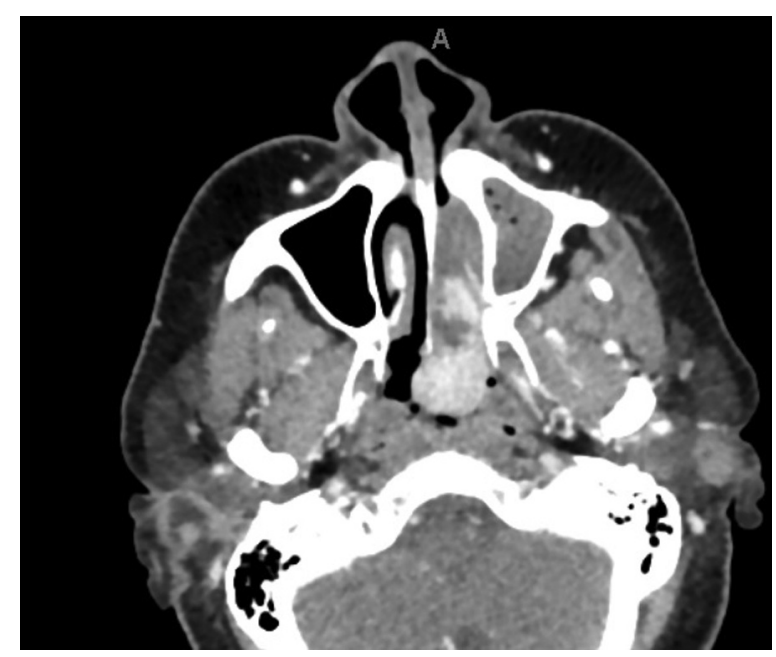

Axial computed tomography reconstructions postcontrast showing a hypervascular mass originating from the left nasal cavity, extending into the nasopharynx.

MRI confirmed the computed tomography findings. The lesion showed hypointermediate signal intensity in T1W images and heterogeneous hyperintense signal in $\mathrm{T} 2 \mathrm{~W}$ images with areas of cystic changes. The lesion was highly vascular showing marked enhancement in the postcontrast scan (Figs 5-7). The magnetic resonance angiography study suggested the arterial supply from the left internal maxillary artery branch (Fig. 8).

Because of the bleeding possibility, preoperative embolization was planned. It was performed the day before the surgery. Angiography confirmed that the main feeding vessel was the internal maxillary artery. Embolization of this vessel was performed to reduce
Figure 2

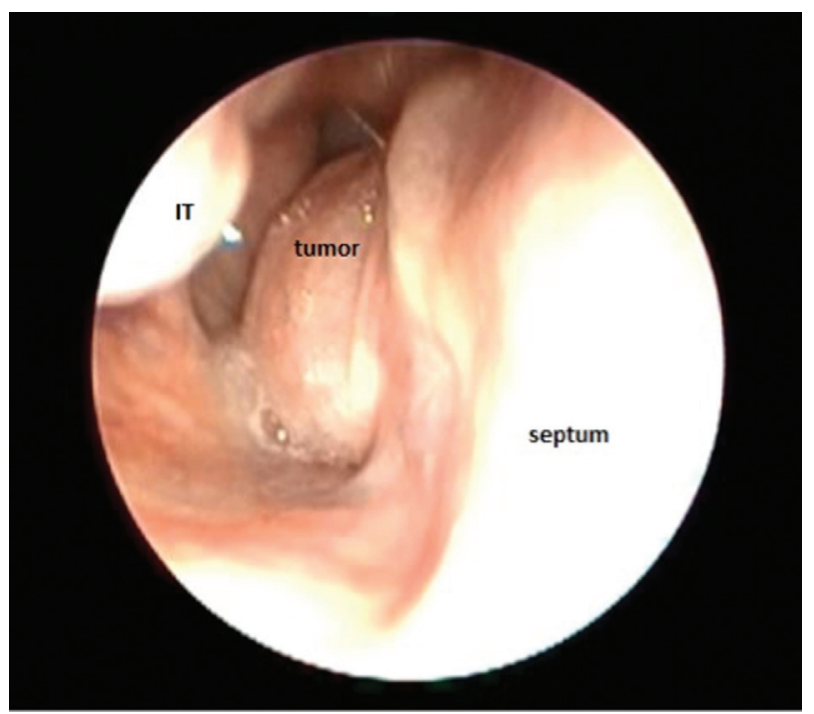

The tumor extends into the nasopharynx and reach the right posterior choana.

Figure 4

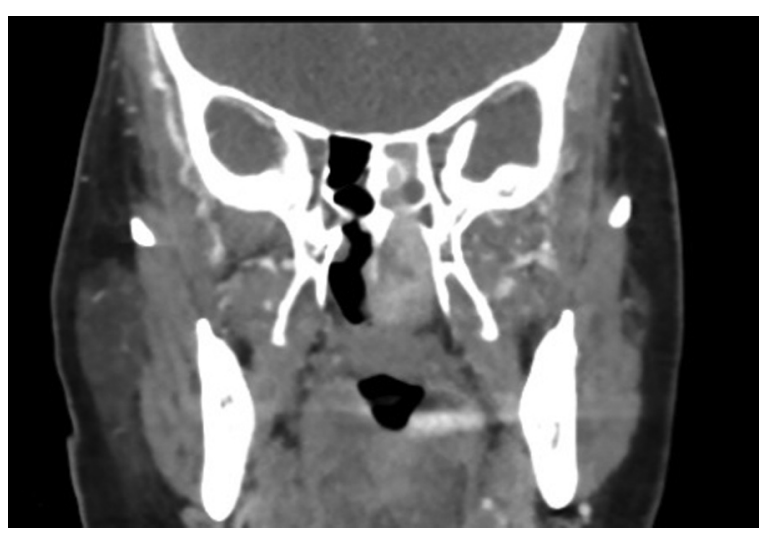

Coronal computed tomography reconstructions postcontrast showing a hypervascular mass originating from the left nasal cavity, extending into the left sphenoid and the nasopharynx.

intraoperative blood loss, facilitating complete excision.

\section{Surgery}

Before surgery, informed consent for the study was obtained from the patient. Complete endoscopic excision of the tumor was performed. The tumor's main point of origin was at the posterosuperior portion of the nasal septum. It was pedunculated, filling the entire posterior nasal cavity and the nasopharynx. It is extended reaching inside the left sphenoid sinus. Bipolar diathermy and the coblation wand were used to excise the tumor from its origin completely. The large size of the tumor prevented its delivery through the anterior naris, therefore, it was 
Figure 5

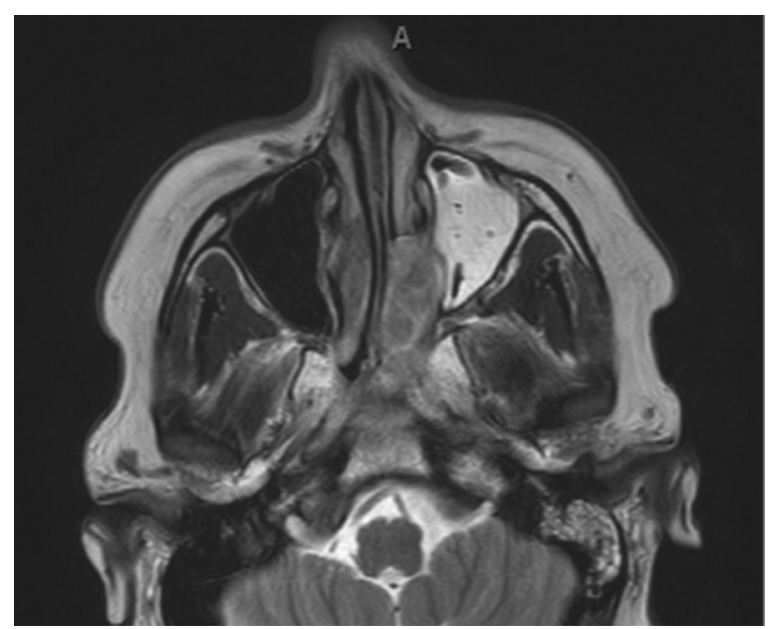

MRI, axial view, T1, Precontrast and postcontrast showing hypointermediate signal intensity with areas of cystic changes. Marked enhancement in the postcontrast is observed.

Figure 7

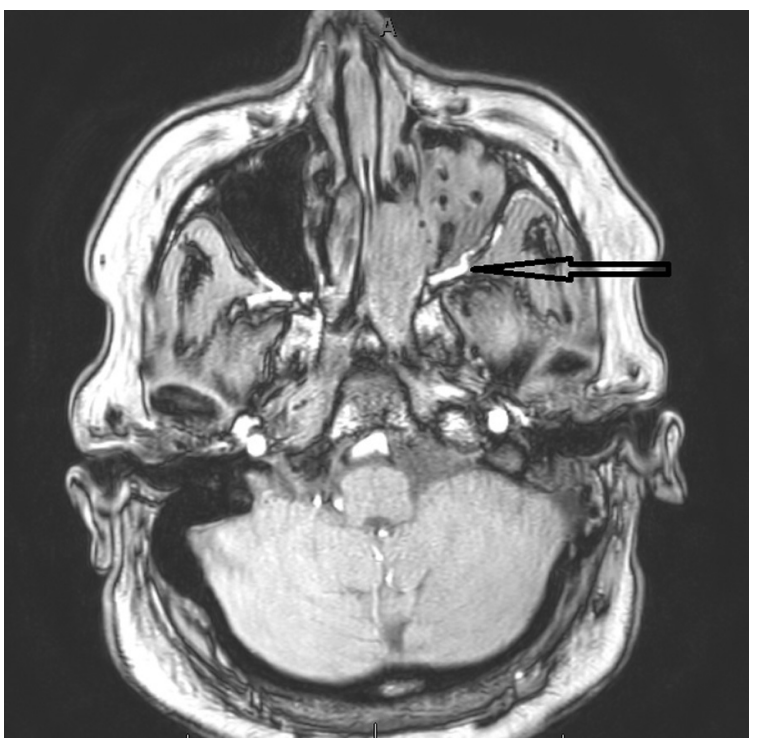

Axial source image MRI postintravenous contrast showing the feeding vessel (arrow) from the left internal maxillary artery.

pushed backward into the oral cavity and was delivered out through the mouth. Left-sided functional endoscopic sinus surgery was performed to aerate the sinuses from secondary obstruction. Minimal bleeding was observed during the procedure.

\section{Histopathology}

The specimen was examined by a histopathologist, who reported that the sections showed an unencapsulated lesion with cells arranged in a diffuse pattern architecture, frequently effacing/enveloping normal structures (Figs 9 and 10). The cells showed whorled, storiform, and reticular arrangements in areas and small capillaries as well as large patulous
Figure 6

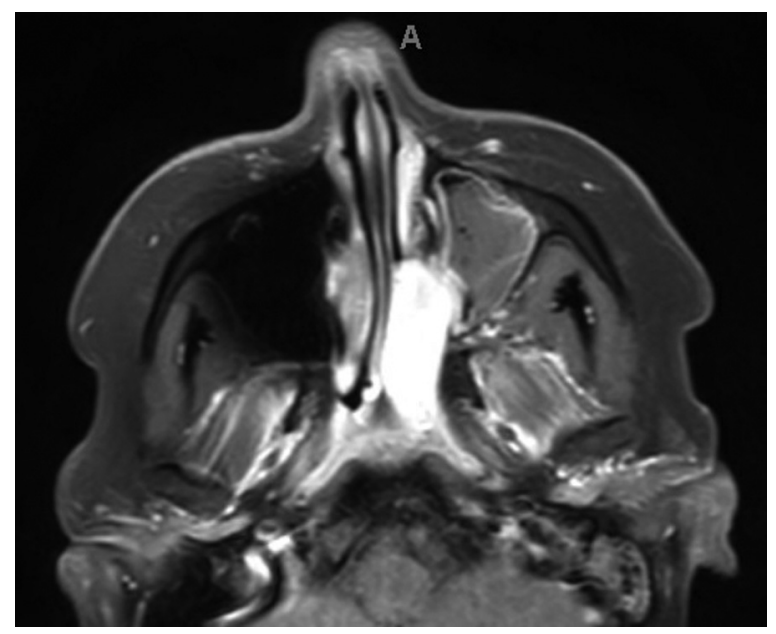

MRI, axial view, T1, post-contrast showing marked enhanced lesion.

Figure 8

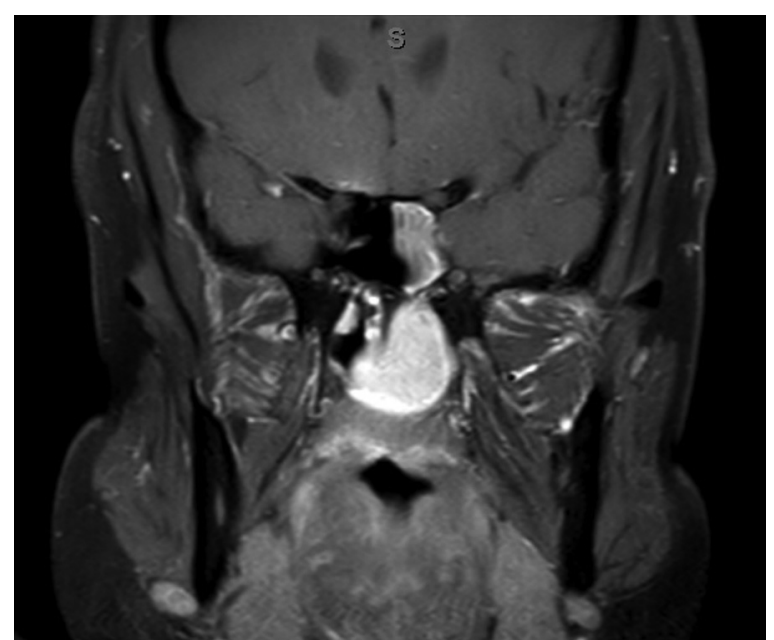

MRI, T1, coronal view shows the mass extending into the left sphenoid sinus and the nasopharynx.

vascular spaces. Areas show a peritheliomatous hyalinization pattern. The cells show a closely packed, syncytial architecture with uniform oval to elongated cells with indistinct cell borders. The nuclei are ovoid to spindly, vesicular to hyperchromatic with nondescript cytoplasm (Fig. 11). Mitosis is very occasional (1-2/10 hpf) and there is no nuclear pleomorphism, apoptosis, or necrosis. Scattered mast cells and eosinophils are seen with extravasated erythrocytes. Ancillary test showed: Immunohistochemistry was done HP1714032 that showed smooth muscle actin positivity and negative for CD34 and S100 (Figs 12 and 13). The final conclusion of the histopathologist was excisional nasopharyngeal vascular mass showed histological features of benign sinonasal glomangiopericytoma (Figs 14 and 15). 
Figure 9

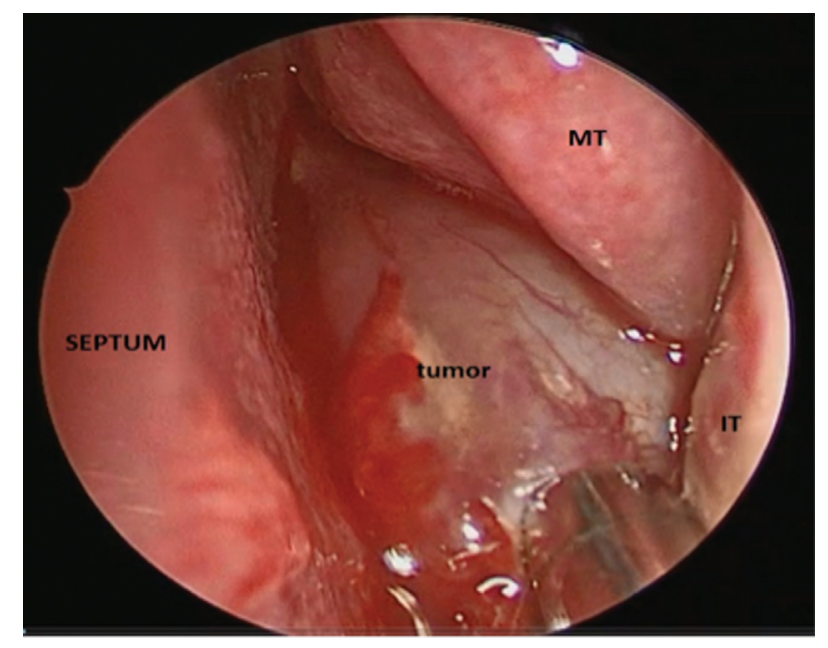

Intraoperative dissection and excision of the tumor. IT (inferior turbinate), MT (middle turbinate).

\section{Figure 11}

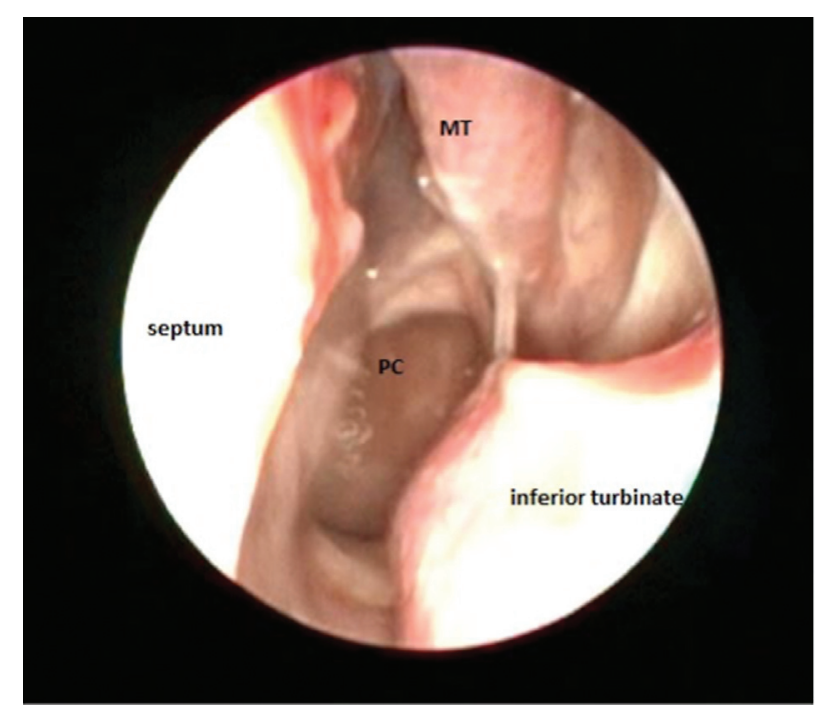

Endoscopic picture 2 months postoperatively. MT (middle turbinate), PC (posterior choana).

\section{Figure 13}

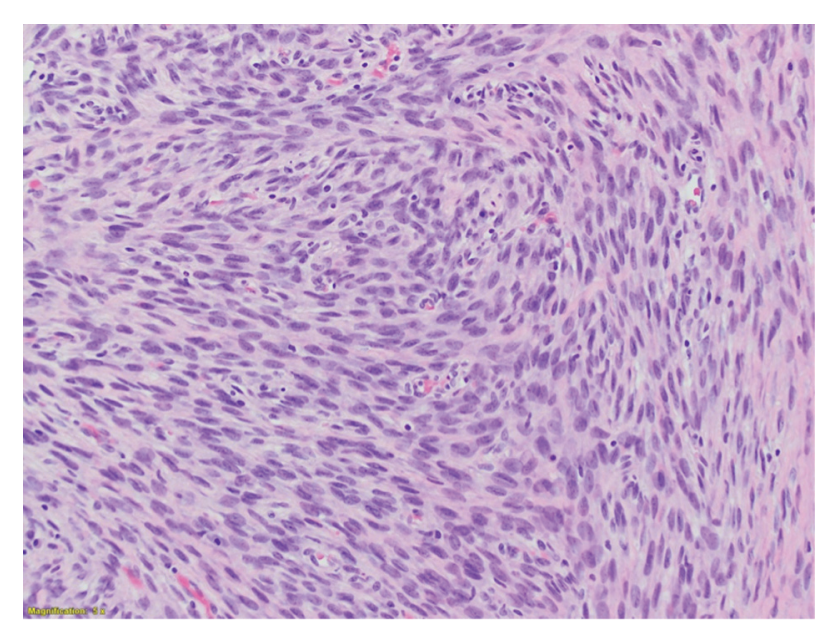

HE stain $\times 20$ showing plump spindly tumor cells.
Figure 10

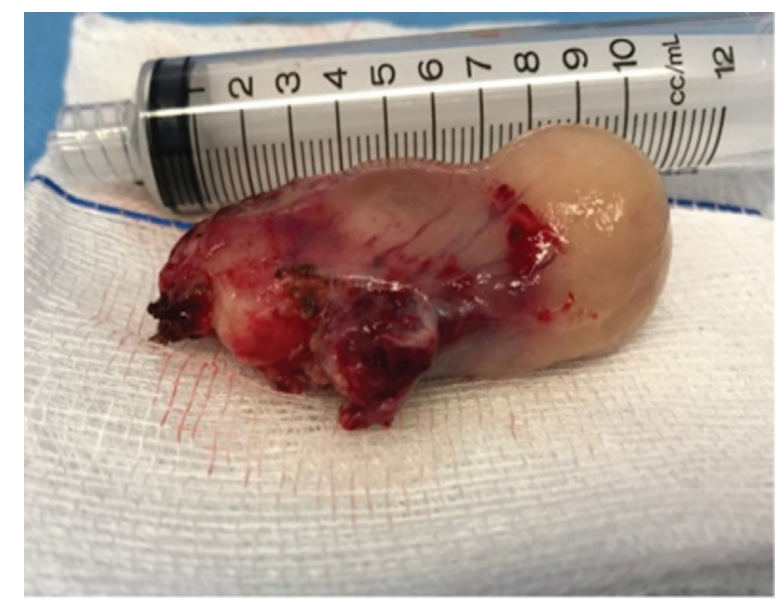

The tumor of $10 \mathrm{~cm}$ in length.

Figure 12

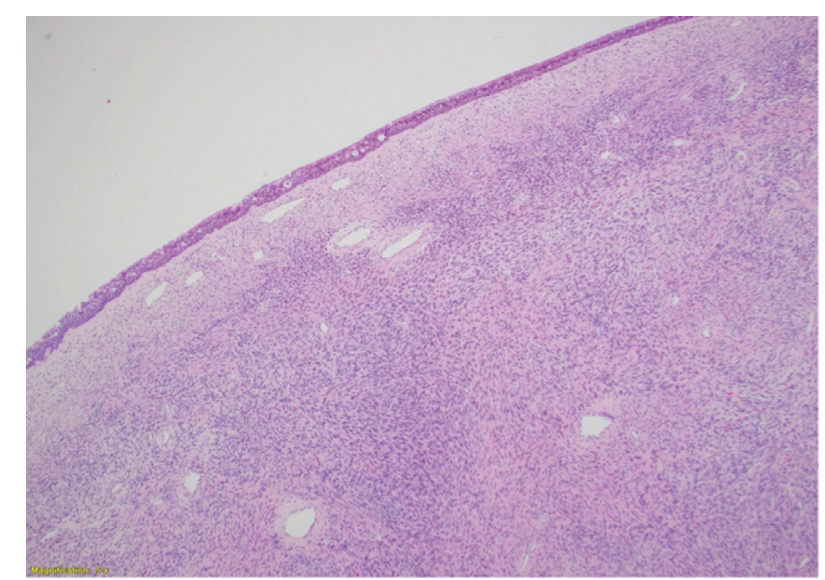

HE stain $\times 40$ showing tumor cells in diffuse pattern.

Figure 14

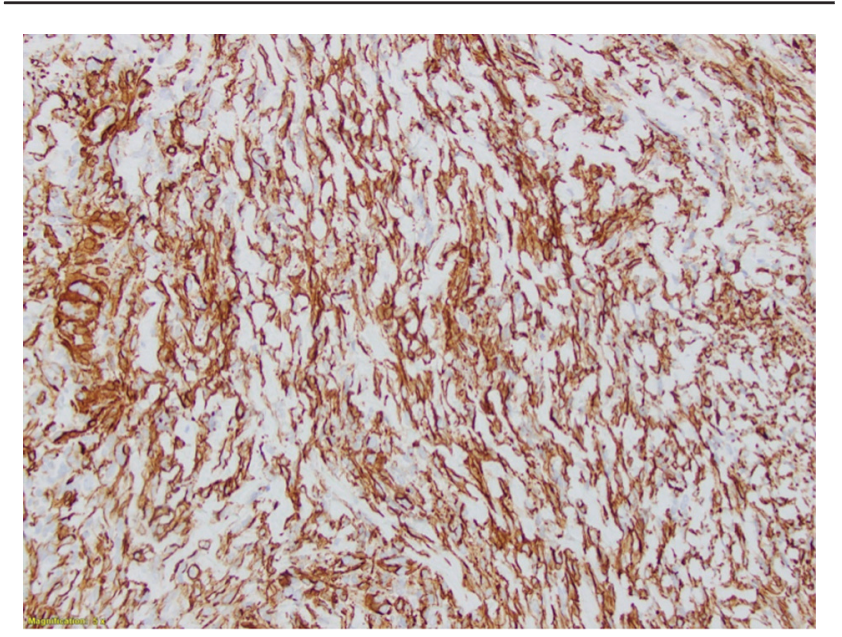

Smooth muscle actin $\times 200$ positive in tumor cells. 


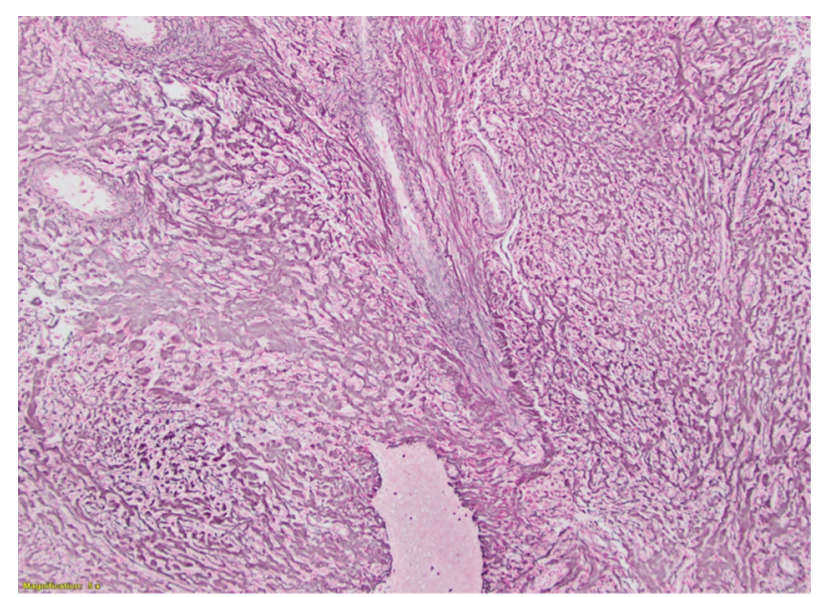

Reticulin stain $\times 100$ highlights the architecture.

\section{Discussion}

Glomangiopericytoma represents less than 1\% of tumors of the sinonasal tract. It arises mainly from the nasal cavity and mostly from the posterosuperior part of the nasal septum. It may extend to reach within one or more of the paranasal sinuses. It is difficult to diffrentiate from other benign or low malignant vascular tumors of the sinonasal cavity such as lobular capillary hemangioma, leiomyoma and angiofibroma, and cellular solitary fibrous tumors $[1,4,7]$.

Glomangiopericytomas affect mainly in the sixth to seventh decade of life with slight predominance in women. It has however been reported at as early as 18 years of age [8].

The etiology of this tumor is still not clear. The predisposing risk factors which may play a role in the etiology include previous trauma, high blood pressure, prolonged use of corticosteroid, pregnancy, and any hormonal imbalance. In the case of our patient there was no report or evidence of the aforementioned risk factors [9-11].

The most commonly reported symptoms are epistaxis and nasal obstruction, as the majority of the neoplasm remains localized within the sinonasal region. Some tumors, however, may extend to reach one or more of the sinus cavities or very rarely into the skull base region. In those extensive tumors, the patient may present with different symtopms like chronic sinus condition, visual disorder, cheek paresthesia [12,13], high intracranial tension, with unilateral proptosis also documented [11].
A rare case of glomangiopericytoma was reported by Gyuet al. [14]. It was discovered in the right maxillary sinus and the tumor was resected by the Caldwell-luc approach. They reported that oncogenic osteomalacia is a very rare possible complication of glomangiopericytoma.

Our study agrees with some authors who recommend angiography and preoperative embolization in large tumors to reduce the risk of intraoperative bleeding $[5,15]$, while others performed excision without.

Distant metastasis is reported to be around 5\% that is very less in comparison to ordinary hemangiopericytomas. A mortality rate of less than $5 \%$ had been reported because of sinonasal hemangiopericytoma $[5,16]$.

With complete removal of the tumor, the expected recurrence is of very low incidence. Combined chemotherapy and radiotherapy are recommended as a palliative treatment for inoperable tumors and for cases which have metastasis. However, the risk of recurrence may happen even after long tumor free interval. This was reported 26 years after tumor resection. So, lifelong follow-up of those patients is recommended as all over recurrence vary from 9.5 to $50 \%[9,16]$.

\section{Financial support and sponsorship}

Nil.

\section{Conflicts of interest}

There are no conflicts of interest.

\section{References}

1 Stout AP, Murray MR. Hemangiopercytoma: a vascular tumor featuring Zimmermanns pericytes. Ann Surg 1942; 116:26-33.

2 Thompson LD, Fanbererg Smith JC, Wenig BM, Barnes L, Eveson JW, Reichart $\mathrm{P}$, et al. WHO classification of tumors. In: $x x \mathrm{xx}$, editor. Pathology and genetics of head and neck tumors. 3rd ed. Lyon, France: IARC Press 2005. pp. 43-45.

3 Thompson LD. Sinonasal tract glomaniopericytoma (hemangiopericytoma). ENT J 2004; 83:807-808.

4 Barnes L, Everson JW, Reichart P, Sidransky D. WHO classification of tumors. In: Barnes L, editor. Pathology and genetics of head and neck tumors. 3rd ed. Lyon, France: IARC Press 2005. pp. 87-90.

5 Tse L, Chan JK. Sinonasalhaemangiopericytoma like tumor: a sinonasal glomus tumor or a haemangiopericytoma. Histopathol J 2002; 40:510-517.

6 Chihani M, Aljalil A, Touati M, Zoubeir Y, Labraimi A, Ammar H, et al. Glomangiopericytoma: an uncommon sinonasal perivascular tumor with particular characteristics. Egypt J Ear Nose Throat Allied Sci 2012; 12:167-170.

7 Compagno J. Hemangopericytoma-like tumors of the nasal cavity: a comparison with hemangiopericytoma of soft tissue. Laryngoscope 1978; 88:460-469.

8 Wang CC, Chu ST. Glomangiopericytoma of nasal cavity: a rare sinonasal perivascular tumor. J Med Sci 2013; 33:107-111. 
9 Ledderose GJ, Gellrich D, Holtmannspotter M, Leunig A. Endoscopic resection of sinonasal hemangiopericytomna following preoperative embolisation: a cased report and literature review. Case Rep Otolaryngol 2013; 2013:796713.

10 Dandekar M, McHugh JB. Sinonasal glomngiopericytoma case report with emphasis on the differential diagnosis. Arch Path Lab Med 2010; 134:1444-1449.

11 Atolini JN, Melotti LF, Yamamotol TY, Lunelli V, Lang GP, Silveira DA, et al. Gllomangiopericytoma: an unusual type of nasosinusal tumor. J Bras Path Lab Med 2017; 53:334-337.

12 Oosthuizen JC, Kennedy S, Timon C. Glomangiopericytoma (sinonasaltype haemangiopericytoma). J Laryngol Otol 2012; 126:69-72.
13 Sun Q, Zhang C, Chen W, He Y. The molecular mechanisms on glomaniopericytoma invasion. Opharnet J Rare Dis 2013; 8: 152-153.

14 Gyu G, Hun JL, Park Y, Ho YH. Sinonasal glomangiopericytoma causing oncogenic ostemalacia. Clin Exp Otorhinolaryngol 2014; 7:145-148.

15 Psoma E, Karkos PD, Dova S, Gavrilidis M, Markou K, Kouskoura C, et al. Sinonasal gloamngiopericytoma treated with preoperative embolisation and endosciopic sinus surgery. Ecancermedicalscience 2016; 10:692-694.

16 Kuvda R, Sharma S, Gurijala R, Nayak DR. Sinonasal type hemangiopericytoma of nasal cavity: a rare neoplasm case report with a brief review of lietrature. RRJMHS 2014; 3:31-36. 